\title{
Direitos de Propriedade da Terra Rural no Brasil: uma proposta institucionalista para ampliar a governança fundiária
}

\author{
Sebastião Neto Ribeiro Guedes ${ }^{1}$ e Bastiaan Philip Reydon²
}

Resumo: $\mathrm{O}$ artigo discute, sob uma perspectiva institucionalista, a dimensão do problema fundiário brasileiro expresso pela fragilidade dos direitos de propriedade da terra rural. Além dos condicionantes históricos referidos no texto, o artigo chama a atenção para o papel das instituições de registro e cadastro de imóveis que, por estarem separadas e não integradas, favorecem as práticas de fraude, apossamento e potencializam os conflitos fundiários. O artigo conclui com uma proposta de mudança institucional, baseada no aumento da governança da terra, no recente contexto favorável ao aperfeiçoamento da estrutura de direitos de propriedade da terra.

Palavras-chaves: Economia institucional, direitos de propriedade, política fundiária, governança fundiária.

Abstract: This paper discusses, based on an institutional perspective, the fragility problem regarding rural land property rights in Brazil. It starts by analyzing historical determinants of the land governance institutional setting, mainly the land registration and land cadastre systems. It shows that it is not adequate for ruling land squatting, it creates incentives for frauds and stimulates land conflicts. The paper ends proposing institutional changes which creates adequate land governance that will assure a security increase in rural land property rights.

Key-words: Institutional economics, property rights, land policy, land registration, land governance.

Classificação JEL: Q13, Q15.

1 Professor Doutor do Departamento de Economia da Universidade Estadual Paulista "Júlio de Mesquita Filho" (Unesp/Araraquara). E-mail: sebaneto@fclar.unesp.br

2 Professor livre-docente do Instituto de Economia da Universidade Estadual de Campinas (Unicamp). E-mail: basrey@eco.unicamp.br 


\section{Introdução}

O problema fundiário - que diz respeito à posse, uso, registro e cadastro da terra - nunca foi tão atual no Brasil. Não há semana em que a grande mídia deixe de noticiar algum fato a ele relacionado ${ }^{3}$. Ao mesmo tempo, o próprio cartório de registro de imóveis vem sendo, enquanto instituição, alvo de críticas. Aponta-se para sua natureza contraditória como serviço público do Estado, delegado à exploração em caráter privado. Argumenta-se que os emolumentos cobrados dos usuários, além de vultosos, não se restringem à remuneração do agente notarial, uma vez que eles estão excluídos do teto remuneratório do serviço público. Do mesmo modo, sobre eles não se aplica a súmula vinculante do STF que veda o nepotismo. Por fim, conforme observou Dias (2009):

Embora não estejam divulgados os dados de 2008, o faturamento dos cartórios do país, em 2006, seria suficiente para bancar toda a despesa prevista no Orçamento de 2009 relativamente à Câmara dos Deputados (R\$ 3.532.811.091), ao Senado Federal (R\$2.742.975.855), ao Ministério do Meio Ambiente (R\$3.460.640.619) ou

3 A Folha de S. Paulo, por exemplo, em edição de 27 de junho de 2008, intitulada "14\% da Amazônia é terra de ninguém", informa que: um levantamento recém-concluído pelo Incra (Instituto de Colonização e Reforma Agrária) revela que o órgão desconhece uma área da Amazônia Legal que, somada, equivale a duas vezes o território da Alemanha ou às áreas dos estados de São Paulo, Rio Grande do Sul e Paraná juntos. O Incra não sabe se esses 710,2 mil quilômetros quadrados estão nas mãos de posseiros ou de grileiros. Nem o que está sendo produzido, plantado ou devastado nessas terras públicas da União. ao Ministério das Relações Exteriores

( $\mathrm{R} \$ 1.891 .740 .902)$.

Esses fatos expressam uma particularidade do momento atual no que diz respeito à política fundiária e às instituições que a amparam: o conflito e a tensão entre a permanência e a mudança nas instituições que lidam com os direitos de propriedade da terra. Apesar de a lei de terras de 1850 ter proibido o instituto da posse como meio para o acesso à propriedade privada da terra, ela é, ainda hoje, um recurso bastante generalizado e um meio pelo qual se embutem expectativas de que, no futuro, o Estado regularizará a situação, trazendo o transgressor ao abrigo da lei.

Assim como no passado, a questão do que é terra pública e o que é terra privada, discriminação que deveria ter sido feita supostamente pela lei de terras, permanece angular no que diz respeito à atual questão fundiária, pois a permanência dessa indeterminação econômico-jurídico-política abre amplo espaço para o avanço privado do domínio público, inviabilizando qualquer política nacional de terras ${ }^{4}$.

O objetivo desse artigo é discutir, à luz da teoria dos direitos de propriedade, como se deu a estruturação dos direitos de propriedade da terra rural no Brasil e como tais direitos evoluíram até hoje. Ao mesmo tempo, dado o contexto no qual se espera que mudanças institucionais sobre registro e cadastro de imóveis ocorram, o artigo apresenta uma proposta de intervenção fundiária cujo

4 Conforme foi observado por Osório Silva (1996 e 1997), Guedes (2006), Rezende e Guedes (2008), Junqueira (1978), Mueller (2006), Reydon (2007) entre outros. 
escopo é o de ampliar a regulação fundiária. A perspectiva defendida nesse texto é a de que mudanças de natureza bastante heterogênea - que dizem respeito à defesa do meio ambiente, a objetivos econômicos de certos grupos sociais ligados aos agronegócios, aliado a interesses específicos de Estado - estão forçando uma nova governança sobre a terra rural no Brasil, acenando para ampliar a segurança dos direitos de propriedade.

$\mathrm{O}$ artigo está dividido em seis itens, incluindo esta introdução. O item 2 apresenta a discussão sobre a teoria dos direitos de propriedade, enfatizando suas descobertas mais recentes, cuja tônica central tem sido os processos de bloqueio institucional que impedem a emergência de estruturas de direitos de propriedade mais eficientes. $\mathrm{O}$ item 3 avança, sobre o caminho pavimentado pela discussão anterior, no sentido de mostrar a importância econômica das instituições de registro e cadastro de terras, bem como suas várias formas institucionais. O item 4 apresenta a trajetória das legislações e da estrutura de registro de imóveis e seu papel na gênese da estrutura fundiária e dos direitos de propriedade no Brasil, desde a Lei de Terras de 1850. No item 5 é apresentada uma proposta de política fundiária, centrada numa reforma institucional para ampliar a governança fundiária, tecnicamente simples e que é politicamente viável no contexto explicitado na seção anterior. $O$ artigo é concluído no item 6, que apresenta as considerações finais.

\section{Instituições e direitos de propriedade}

A teoria dos direitos de propriedade surgiu nos anos 60 do século $X^{5}$ como parte da agenda de pesquisa, vanguardeada por Coase, de instrumentalizar, com o aparato teórico da escola neoclássica, a afirmação genérica da velha

$5 \mathrm{Na}$ verdade, essa afirmação deve ser relativizada, pois Commons, nos anos 30 do século XX, empregou o termo e o utilizou na análise econômica de modo, é verdade, distinto daquele proposto por Coase e seus seguidores. É provável, contudo, se se der crédito à genealogia do termo feita pelo próprio Commons, que ele tenha sido utilizado pela primeira vez em economia por MCLEOD, em 1856. A respeito disso, ver Commons (2003). escola institucionalista norte-americana de que as "instituições importam".

O ponto de partida da discussão dos direitos de propriedade foi o célebre artigo de Coase, (1988) publicado em 1960, e intitulado "The problem of social cost", que discutiu criticamente a teoria econômica do bem-estar na sua versão dada por Pigou. Os argumentos e conclusões desse artigo ficaram conhecidos como Teorema de Coase porque afirmavam que, dadas algumas hipóteses restritivas, o processo de troca baseado no autointeresse produzirá uma única e economicamente eficiente alocação de recursos, independentemente da distribuição inicial de direitos de propriedade. Em outras palavras, se um ativo pode ser mais produtivamente empregado por fulano do que por sicrano, a venda dos direitos de propriedade deste para aquele melhoraria a posição relativa de ambos e restauraria a eficiência.

Todavia, a percepção de que a operação dos mercados envolve significativos custos de transação fez deslanchar a pesquisa na área de direitos de propriedade (GREIF, 2003). Por direitos de propriedade se entende, em geral, o sistema de normas e leis que autoriza/proíbe o uso de determinado recurso, constituindo instrumentos de incentivo/desincentivo sobre o comportamento humano (BROCKMEIER, 1998) .

A teoria afirma que a troca não é meramente a transferência de bens e serviços de uma mão para outra, como acreditava a tradição em economia, mas a transferência de direitos sobre a posse, uso e disposição daqueles bens, implicando, portanto, num papel relevante da lei e do Estado (uma vez que é ele quem impõe os direitos de propriedade, pressupõe-se, também, que ele deva ser forte). Identificava, ademais, uma cristalina relação entre direitos de propriedade e a eficiência no uso de recursos escassos, sendo possível verificar que onde tais direitos são claros, bem delimitados e protegidos pela ação do Estado, verifica-se maior e melhor performance no seu uso, e vice-versa. Ao mesmo tempo, a teoria declarava, implícita ou

\footnotetext{
6 Definições convergentes podem ser encontradas em Alston (1998), Fishel (1985), Cole e Grassman (2002).
} 
explicitamente, que o processo histórico reservou à propriedade privada a forma por excelência da propriedade, pois ela contém os mecanismos de incentivo e de apropriação individual de resultados mais condizentes com a eficiência e eficácia econômicas (BINSWANGER; PINGALI, 1986; JOHNSON, 1972).

O ponto de partida dos estudos com essas características foi o artigo de Demsetz (1967). Nele, o autor chamou a atenção para a importância dos direitos de propriedade para a análise econômica, porque eles formam as expectativas (na forma da lei, costumes e moral) que os indivíduos podem razoavelmente sustentar em seu intercâmbio com os outros. Conforme Demsetz (1967), a função dos direitos de propriedade é a de orientar incentivos para viabilizar uma maior internalização das externalidades. Os direitos de propriedade emergem quando os direitos antigos não se ajustam às mudanças em: 1 ) tecnologia (novos produtos, processos e mercados) e 2) preços relativos. Esses são, grosso modo, os fatores de mudança nos direitos de propriedade.

O exemplo dos índios da Península de Labrador, no Canadá, é utilizado para ilustrar sua tese. Sustentado em estudos de antropologia sobre essa comunidade indígena, Demsetz observou que, antes do contato com o colonizador e da introdução do comércio de peles, a terra era um bem livre, onde os índios podiam caçar livremente, em geral para propósitos de autoconsumo, sendo pequena a quantidade de peles requerida pelas famílias. Embora houvesse externalidade, ela era pequena e desconsiderada pela comunidade. Com o advento do comércio, surgiram duas consequências. Primeiro, um aumento significativo no preço das peles e, segundo, um sensível aumento na escala da caça. O resultado foi que as externalidades se elevaram (o aumento da caça de um indivíduo reduzia a do outro, reduzindo, no longo prazo, o montante total de caça disponível para a coletividade), incentivando a mudança nos direitos de propriedade. Os direitos de propriedade evoluíram, então, em direção a maiores especificações, culminando com a definição mais estrita de direitos de propriedade de tipo propriedade privada.
No interior dessa perspectiva ainda está a contribuição de North (1990), para quem os direitos de propriedade definidos pelo Estado e por instituições de ordem pública são necessários para que os mercados sejam estruturados e funcionem. Alston (1998), no mesmo sentido, reconhece que a natureza dos direitos de propriedade influencia o desempenho econômico porque ela determina os custos de transformação e de transação?

A aplicação da teoria a estudos de caso tem sido ampla e variada (GREIF, 2003). No que diz respeito àquela parte desses estudos que envolvem a terra e seus usos há uma literatura não menos vasta; por exemplo, ao analisar as mudanças no regime de propriedade da terra no México, Vogelgesang (1996) mostrou como a estrutura de direitos de propriedade evoluiu recentemente dos ejidos para a propriedade privada plena, como resultado da liberalização comercial e da constituição da Alca, que criou um mercado comum entre, fundamentalmente, EUA e México. Conclusões muito semelhantes também sobre o México alcançaram Gordillo; De Janvry; Sadoulet (1999). No Brasil, vários estudos vêm sendo publicados, cabendo referir aqui aos de Mueller (2006), Azevedo; Bialoskorky (2002) ${ }^{8}$.

Reflexões mais recentes da teoria têm abandonado os pressupostos de maximização presentes nas primeiras versões da teoria e chamado a atenção para a persistência de direitos de propriedade que oferecem um nível menor de eficácia e eficiência do que arranjos alternativos. Liebcap (1998) observou que os processos que definem e impõem os direitos de propriedade - determinados por processos políticos - têm implicações distributivas sobre a alocação de riqueza e poder, gerando perdas e ganhos aos grupos sociais envolvidos. Conforme a natureza e intensidade desses efeitos e do poder relativo das partes engajadas no processo

7 Eggertsson (1990) argumenta que o ambiente institucional influencia o desempenho econômico e o bem-estar social porque age sobre a estrutura de incentivos das firmas, estimulando ou não a incorporação de progresso técnico e uma melhor distribuição de renda.

8 Para um balanço da utilização no Brasil do arcabouço institucionalista aplicado aos estudos em economia agrícola ver Belik; Guedes; Reydon (2007). 
de mudança, os ganhos agregados de reduzir os problemas de propriedade de comuns e os ganhos com o crescimento econômico oriundos de mudanças nos direitos de propriedade podem ser bloqueados, preservando a continuidade de arranjos de direitos de propriedade ineficientes.

Um caso interessante estudado por Liebcap diz respeito à incapacidade dos grandes pecuaristas e madeireiros norte-americanos de modificarem a lei de terras em seu favor. Eles lutaram para modificá-la, reivindicando que as terras transferidas da União tivessem uma área maior do que os costumeiros 160 acres, além de solicitar a eliminação da necessidade de comprovar sinais de melhoria agrícola, tais como a construção de casa de moradia e o cultivo. Antes de 1880, na vasta região noroeste dos EUA, o arranjo de propriedade era tal que podia prescindir de maior especificação. Os pecuaristas simplesmente se apossavam de grandes áreas de terras de pastagem e institucionalizaram mecanismos informais entre si de reconhecimento e imposição de direitos de propriedade com base na antiguidade da posse. Os madeireiros recorreram a instrumentos mais evasivos, utilizando-se de testas de ferro que reivindicavam terras gratuitamente no contexto da Lei do Homestead para, posteriormente, após o recebimento do título, transferi-lo para as empresas madeireiras. Após 1880, contudo, a pressão por novos assentamentos e a competição por terra exigiram maior segurança jurídica, o que somente poderia acontecer, em sua opinião, com a instituição da propriedade privada. Daí a iniciativa desses grupos sociais de modificar a lei. Eles esbarrariam, no entanto, em dois tipos de obstáculos que neutralizaram seus objetivos de mudança institucional. O primeiro foi que embora houvesse perda decorrente da insegurança jurídica, ela não foi suficientemente grande a ponto de pressionar o Congresso para estabelecer mecanismos de barganha sobre os ganhos agregados de um acordo. O segundo obstáculo residia no fato de que a proposta dos dois grupos modificaria uma ênfase há muito tempo estabelecida na política de privilegiar pequenos lotes (160 acres) para agricultores familiares, que teriam limitado seu acesso à terra caso as mudanças propostas fossem aprovadas.
O texto de Liebcap flagra uma situação na qual a fuga das restrições governamentais foi feita por meio da fraude, no caso dos madeireiros, e da posse ilegal de terra pública, no caso dos pecuaristas, resultando ambos em enorme dissipação de recursos que teriam sido poupados se as terras tivessem sido vendidas sem restrições de tamanho aos compradores.

Nessa mesma perspectiva, Joireman (2001), em interessante estudo sobre a Etiópia, revelou casos de bloqueio por parte do Estado de mudanças nos direitos de propriedade das comunidades Sidamo e Shoa, cujos resultados, por favorecerem grupos sociais poderosos, preservaram instituições econômicas menos eficientes. De uma perspectiva marxista, o artigo de Khan (2004), dedicado ao estudo de Bangladesh, identificou, na persistência de instituições agrárias ineficientes, o bloqueio por parte de facções poderosas engajadas na acumulação primitiva.

Essas descobertas de fatores de bloqueio que impedem a adoção de uma estrutura institucional mais eficiente para a alocação de direitos de propriedade, com seus efeitos negativos sobre o uso dos recursos produtivos, têm particular relevância porque auxiliam no entendimento dos motivos da persistência de direitos de propriedade menos eficientes, mesmo quando existe alternativa melhor?. Elas chamam também a atenção para a importância de instituições informais e seu papel na estruturação dos direitos. Elas se mostram adequadas, também, aos propósitos de se entender a permanência, no Brasil, de instituições agrárias de direitos de propriedade menos eficientes.

\section{Cadastro e registro de imóveis como instituições}

Os estudos de Soto (2000), Deininger (2003), Galiani e Schargrodsky (2005) têm afirmado que a existência de segurança dos direitos de propriedade é crucial para assegurar maior eficiência econômica no uso da terra, além de garantir estabilidade política e social, reduzindo os conflitos

\footnotetext{
9 Para uma visão de estudos empíricos com essa perspectiva e que envolvem outros setores/atividades não agrárias/ agrícolas, ver Alston (1996) e Liebcap (1989).
} 
em torno da terra. O impacto da segurança dos direitos de propriedade sobre a pobreza é mais controverso e tem sido objeto de vasta literatura, sintetizada por Galal e Razzaz (2001).

No que diz respeito ao papel do regime de cadastro e ao sistema de registro de imóveis sobre a eficiência alocativa de direitos de propriedade, há relativo consenso em torno do seu papel crucial em pelo menos três dimensões. Primeiro, em seus efeitos sobre o desenvolvimento do sistema financeiro, viabilizando o uso da terra legal como garantia hipotecária; também sobre o crescimento econômico em geral, ao impulsionar o investimento, reforçar uma alocação mais eficiente e menos custosa dos recursos e transformar a terra em um ativo; por fim, ela afeta o bem-estar ao reduzir ou eliminar o conflito fundiário. Ou seja, por ancorar expectativas de ganho sobre bases sólidas e seguras em relação aos direitos de propriedade.

Sobre as duas primeiras dimensões deve-se mencionar o artigo de Byamugisha (1999), que trata do papel do registro de imóveis no desenvolvimento econômico. $\mathrm{O}$ artigo recorre a um modelo econométrico para verificar como uma medida direta de direitos de propriedade - os registros de imóveis rurais - se relaciona com o crescimento econômico. $\mathrm{O}$ autor insiste em que os efeitos do registro de imóveis são positivos e não se circunscrevem ao âmbito setorial (rural), mas espalha-se por todo o corpo do sistema econômico.

De outro lado, há evidências suficientes para afirmar que direitos de propriedade mal definidos ou resguardados, por inadequado funcionamento do regime de cadastro e de registro de imóveis, produzem, além de ineficiência produtiva, enorme redução do bem-estar, por conta da proliferação de conflitos fundiários. No Brasil, dados do Ministério do Desenvolvimento Agrário (2008) apresentam cifras expressivas. Segundo elas, somente em 2007 foram verificadas 1.027 ocorrências de ocupação de terras e 24 mortes decorrentes de conflitos agrários. Além disso, há evidências de que a atuação dos cartórios é, em muitas circunstâncias, instrumentalizada para beneficiar a grande propriedade ou o grande capital, em detrimento do pequeno proprietário/posseiro.
O livro de Moraes Silva (1999) revela em detalhes o processo sistemático - levado a cabo com o auxílio da lei e dos cartórios - de expropriação dos pequenos posseiros que ocupavam secularmente terras do Vale do Jequetinhonha antes da "modernização trágica" que os acometeu no início dos anos 70 do século XX.

A importância das instituições do cadastro e registro de imóveis rurais para a segurança patrimonial foi realçada de maneira muito precisa também por Dekker (2003) e (2005). Para ele, a natureza dos bens imóveis é bem distinta dos móveis em pelo menos dois aspectos. Os primeiros não podem ser levados com seu possuidor como meio de atestar a propriedade/posse do bem, como se faz, por exemplo, com uma garrafa de vinho. Ademais, eles não podem ser ocultados por exemplo, guardados em uma adega ou em uma sacola - da cobiça alheia, pois estão ali, fixos, imóveis, visíveis para todos da comunidade. Quando transferida de uma mão para outra, não é a terra que se movimenta, mas os direitos sobre ela. Por isso que a terra exige, mais do que qualquer outro bem, mecanismos específicos de salvaguardas em relação ao processo de transferência. Como saber que a terra foi realmente transferida? Para quem? Como?

Dekker (2005) demonstrou que transferências e negociações envolvendo a terra são muito antigas, bem como alguns mecanismos de demarcação e registro. $\mathrm{Na}$ antiguidade, pareceu uma regra que transferências de direitos de propriedade necessitavam de testemunhas, não raro do chefe ou do conselho de sábios da comunidade, que avalizavam a negociação, oferecendo-lhe algum tipo de sanção coletiva. Antes do uso da escrita para propósitos de registro, vários outros instrumentos foram utilizados, com efeitos simbólicos, tais como o ato de o vendedor retirar e dar suas sandálias ao comprador; guardar o comprador uma telha que cobria a casa do vendedor ou quebrar, com testemunhas, um galho na terra vendida. Apesar de o registro de casos de transferências de direitos de propriedade da terra ser antigo, essa prática não era comum nem ensejou o desenvolvimento de um mercado de terras. 
Na verdade, em uma sociedade ou comunidade onde a vida econômica e social implicava em pequenas e esporádicas relações mercantis e onde a terra jamais se tornou uma mercadoria no sentido moderno, o cadastro e registro exatos da terra eram desnecessários e contraproducentes. A concessão de uso da terra se transmitia aos descendentes nas exatas condições herdadas pelo atual produtor e o controle de acesso e uso da terra era definido pela comunidade, baseado na tradição e nos costumes ancestrais.

Apesar de, como vimos, ser antiga a necessidade de cadastrar e registrar a terra e garantir o reconhecimento público dos direitos de propriedade, essa necessidade não tem origem nas motivações privadas de negociar a terra ou seus produtos. Ao contrário, tal iniciativa parece ter surgido, pelo menos é o que nos informa Dekker (2003) a respeito da Europa medieval, do Soberano/Estado medieval interessado em ver a terra dos seus súditos demarcada e registrada, permitindo a individualização das parcelas de terra e de seu proprietário/ocupante, para fins de tributação. Sabendo onde estava o lote de terra, seu tamanho, o que nele era produzido e quem o ocupava, o soberano poderia cobrar tributos sobre a terra ou seus produtos. Sendo a terra o recurso produtivo e de poder mais importante, quando não o único, o financiamento dos gastos do soberano deveria provir de parte do rendimento da terra ou de seu produto. Foi em reação a isso que os próprios agentes se colocaram contra e resistiram, o quanto puderam, às investidas de controle e à voracidade tributária do soberano medieval. Em outras palavras, para o cidadão comum do medievo inviabilizar a instituição de um sistema de medida e registro homogêneo era vital para fugir à sanha fiscal do soberano.

No entanto, à medida que se desenvolvia o comércio e se estabeleciam as bases institucionais de funcionamento do mercado, a terra perdia importância econômica relativa como base da tributação (porque lentamente iam aparecendo outras atividades econômicas com potencial de transformar-se em fontes de tributação, por exemplo, o comércio e o artesanato/manufatura estabelecidos nos burgos), ao mesmo tempo em que ganhavam outras e relevantes funções, entre as quais a de tornar-se uma mercadoria como qualquer outra, podendo ser comprada e vendida. Nesse estágio, registro e demarcação precisos de imóveis rurais passaram a convergir com os interesses econômicos emergentes, calcados nos mercados. A razão tributária que orientou no passado a necessidade de registrar e demarcar as propriedades rurais cedeu lugar à razão mercantil de permitir a viabilização da transferência de direitos de propriedade de bens imóveis, cuja particularidade, como já foi comentada, exigia a necessidade de atestar, para o público em geral, que ela é de sicrano, e não de beltrano, e é daquele o direito exclusivo de usar e dela dispor.

Em países capitalistas, onde predomina a propriedade privada, o registro de imóveis tem importância óbvia para a questão fundiária, por estar associada diretamente à constituição, regularização e reconhecimento dos direitos de propriedade. É crucial também para viabilizar políticas públicas que envolvem a terra, tais como de reflorestamento, de proteção do meio ambiente, de ocupação produtiva sustentável de atividade econômica, de assentamentos de reforma agrária, de utilização de terras públicas para recreação e lazer, entre outras.

O processo histórico cuidou para que houvesse vários tipos de cadastro e registro de imóveis rurais. Nos EUA, por exemplo, tanto o cadastro quanto o registro de imóveis são oferecidos como serviços públicos pelo Estado. A instituição responsável, desde 1812, é o Escritório da Terra, subordinado, hoje, ao ministério do interior daquele país. Além de administrar 176 milhões de acres de terras de pastagem, oferecer programas de administração ambiental e florestal, garantir a oferta de áreas públicas de recreação e lazer, emitir licenças para exploração privada sob concessão de terras públicas, o Escritório de Terras, nas palavras de Clawson (1971), tem:

Várias outras atividades, herdadas do passado, que são de importância básica não só para o Escritório da Terra, mas para todos aqueles que possuem ou usam 
a terra. Elas são a pesquisa cadastral de terras, o registro de terras, a classificação das terras e a distribuição da terra. Em qualquer tipo de programa de administração da terra, é essencial identificar a terra em seus contornos físicos e dela ter registros que mostram, clara e decisivamente, o status do título da terra. Isto é verdade tanto para terras particulares quanto públicas. Embora aqueles familiarizados com o registro de terras dos EUA estejam conscientes de suas deficiências, os EUA têm felizmente um sistema de cadastro e registro de terras superior ao de muitos países (p. 48).

Complementarmente no caso norte-americano, há que se referir, conforme Rezende (2006) e Rezende e Guedes (2008) ao papel crucial que esse sistema de registro realizou na promoção do crédito fundiário hipotecário e na formação de um mercado secundário de terras, de não pouca importância na democratização do acesso à terra.

Na Europa, por sua vez, predominam vários sistemas diferentes de cadastro e registro de imóveis. Dekker (2003) identificou pelo menos três, e os denominou de registro de terras com efeito negativo baseado em escritura, registro de terra com efeito positivo baseado em escritura e registro de terras baseado em registro de títulos com efeito positivo. O primeiro é típico da França, Bélgica e Holanda e é baseado na apresentação, por particulares (comprador e vendedor), a um órgão registrador (público), de escritura mostrando a transferência de direitos da terra. Este órgão copia os dados relevantes (conforme a lei estipula) em registros públicos confirmando os dados acerca da intenção de se transferir a terra, mas não dá prova da legalidade dessa transação. A matrícula é apropriada a uma rápida transferência, uma vez que nenhuma interferência do governo é exigida quando todos os documentos apresentados mostram que as partes agiram em acordo com a lei. $\mathrm{O}$ efeito negativo significa que a escritura descreve a intenção das partes envolvidas, mas que os fatos registrados podem ser rejeitados por uma terceira parte. Conforme Dekker (2003)

Na França, por exemplo, é obrigatório que a escritura seja feita por um notário e o envolvimento desse funcionário designado pelo governo (o que torna o notário do continente europeu diferente de seu colega de mesma designação inglês e norte-americano) garante que a escritura seja cuidadosamente preparada. Erros raramente ocorrem e a obrigatoriedade de checar transferências anteriores e os dados sobre os direitos conservados (a assim chamada cadeia de títulos) pelos notários antes que seja lavrada a escritura faz com que o registro de terras na França (e também na Bélgica e Holanda) bastante confiável (p. 187).

O segundo tipo de registro é comum na Dinamarca e nos países escandinavos. Trata-se de um regime de registro no qual o registro nacional de terras do Estado é a única prova judicial de propriedade e não pode ser questionado, dando a este tipo de registro seu efeito positivo.

O terceiro tipo, muito semelhante ao segundo, predomina na Inglaterra e no País de Gales. Nele os dados registrados nos escritórios de registro de terras de sua majestade e refletem a situação legal real da propriedade. Um proprietário de direitos à terra nesses países recebe um título de terra depois que o escritório investigou e processou o pedido para tornar-se o novo legítimo possuidor de direitos à terra.

Do mesmo modo, há várias maneiras de arquivar as informações cadastrais e os detalhes sobre as propriedades, refletindo as diferentes formas como estas são percebidas. Em termos gerais, são duas as principais: uma mais focada nos aspectos legais e outra nos aspectos fiscais. A primeira chamada de registro de terras ou sistema de livro da terra, normalmente é onde se concentram os direitos associados à terra. $\mathrm{O}$ segundo tipo é o cadastro propriamente dito e frequentemente 
contém informações sobre o tamanho físico, a forma, a data, os valores e os usos da terra.

O processo de registrar os direitos legais sobre a propriedade da terra se dá por meio dos seguintes mecanismos: a) registro do documento de compra e venda; b) registro do título da propriedade ou c) outro documento associado ao direito de propriedade. Com frequência, os títulos registrados dos imóveis têm como suporte mapas topográficos, que não necessariamente têm as divisas legais ou mapas cadastrais, pois são oriundos da taxação e não do registro dos imóveis. Em geral, os cadastros podem ser descritos como legal (com foco na propriedade), fiscal (voltado aos valores da terra e do imóvel para taxação), uso da terra (armazenando as diferentes formas como a terra é usada) e multiuso (utilizado para diferentes objetivos). Em alguns países, o termo "cadastro jurídico" se refere a poucas informações, enquanto em outros há uma quantidade maior de informações. Em alguns países há vários cadastros com informações semelhantes ou com duplo registro.

Um elemento-chave em muitos sistemas de informação fundiários são os mapas ou plantas cadastrais. Estes têm a função de localizar o imóvel e fornecer informações sobre o mesmo. Os mapas cadastrais podem dar suporte a um livro de registros de imóveis, referindo-se a um imóvel em particular, ou a vários imóveis em uma região para identificar cada um deles. Neste último caso, pode ser menos preciso em termos de definição dos limites, mas mesmo assim ter valor jurídico (UN-ECE, 1996).

\section{Breve histórico dos fundamentos legais e institucionais para a ausência de regulação adequada nos mercados de terra no Brasil}

Este tópico apresenta, muito rapidamente, como se constituiu e evoluiu historicamente a gestão fundiária no Brasil. Após o fracasso do experimento das capitanias hereditárias, a coroa portuguesa instituiu na colônia brasileira, tendo em conta a experiência de relativo êxito em Portugal, o sistema de propriedade da terra conhecido como sesmaria. Nesse regime, a coroa cedia gratuitamente a particulares o direito de propriedade da terra mediante a observância de que fosse efetivamente ocupado e produtivamente utilizado, caso contrário voltava, por meio de cancelamento da concessão, ao patrimônio da coroa (OSÓRIO SILVA, 1996). Embora fosse do ponto de vista legal a única forma de adquirir a propriedade da terra, outro instrumento foi amplamente utilizado, por grandes e pequenos: a posse. Esses dois institutos um "legal" e outro de "fato" - foram efetivos na ocupação territorial brasileira e, em que pesem as várias tentativas da coroa portuguesa de colocar fim ao descalabro fundiário, explicam a dinâmica fundiária no Brasil. Osório Silva (1996) viu na posse e na incapacidade da coroa portuguesa de impor uma gestão fundiária mais ordenada uma situação funcionalmente adequada aos interesses dos grandes proprietários (muitos na verdade posseiros) que, dada a baixa incorporação de progresso técnico à atividade de base agrária que realizavam, necessitavam de um território amplo e acessível, para o qual se dirigiam, dele se apossando, tão logo a fertilidade natural do solo onde haviam se estabelecido se esgotava.

Somente após a Independência do Brasil (1822) e a pacificação que se seguiu pôde o novo Estado brasileiro pretender instituir a propriedade privada plena da terra e exercer uma política fundiária com o mínimo de controle sobre a ocupação do território. Isto aconteceu com a Lei de Terras (1850), cuja regulamentação ocorreu apenas em 1856. Essa lei deve ser entendida no contexto mais geral de estabelecimento de leis que colocavam restrições ao acesso à terra em todo o mundo colonial ${ }^{10}$. Seus principais objetivos foram:

a) Organizar o acesso à terra;

b) Eliminar a posse;

c) Estabelecer um cadastro de terras para definir áreas devolutas (do Estado);

d) Transformar a terra em um ativo confiável para uso como garantia.

10 Como na Austrália, por exemplo. 
Mas em razão dos interesses dos proprietários do País, a Lei de Terras manteve aberta a regularização das posses, possibilitando a ocupação de terras devolutas e inviabilizando o estabelecimento de um cadastro. Além da usucapião (que estabelece que após alguns anos o posseiro pode regularizar sua propriedade), os próprios estados (ou províncias) em alguns momentos históricos concederam propriedades com ou sem títulos.

Em 1864, uma nova obrigação institucional estabeleceu uma tradição que perdura até os dias de hoje e que acaba por gerar maior indefinição e incapacidade de se regular efetivamente o mercado de terras: a necessidade de se registrarem as posses e as propriedades nos cartórios. De alguma forma, o registro no cartório dá ares de legalidade ao imóvel sem que haja qualquer mecanismo que garanta isso. $\mathrm{O}$ processo de falsificação de posses e de propriedades pelo setor público e dentro dos cartórios brasileiros é comum e generalizado ${ }^{11}$.

A Proclamação da República em 1889 e, com ela, a descentralização político-administrativa, favoreceu a prática da regularização fundiária, uma vez que os Estados ganharam toda a terra devoluta (pertencente ao Estado) e puderam dela dispor livremente. A liberalidade na gestão do patrimônio territorial herdado variou de estado para estado, mas independentemente disso criou mais uma ambiguidade na concessão de títulos e consequentemente incapacidade de regular o mercado de terras ${ }^{12}$.

Foi a promulgação do Código Civil em 1916, no entanto, que gerou a incapacidade de se regularem efetivamente os mercados de terras no

11 No passado mais distante, isso é verdadeiro para o Rio de Janeiro. Segundo Friedman (1999): “vimos que a grilagem fez parte da evolução urbana carioca desde a época colonial, quando as ordenas religiosas, nobres e funcionários da Câmara já falsificavam escrituras e documentos..." (p. 296).

12 Apesar disso, houve preocupação em regular a terra atestada pela tentativa frustrada de regulação da propriedade através do Registro Torrens (1891), segundo o qual os posseiros e proprietários poderiam obter o título definitivo por meio de petição não contestada. Por outro lado, a possibilidade de legalização das posses em 1895 e em 1922 (referentes às posses entre 1895 e 1921) acabou por criar as condições para que as posses perdurem e se enfraqueça a regulação do mercado de terras como expresso na Lei de Terras de 1850.
Brasil, tanto por reafirmar o cartório com a instituição de registro como por possibilitar que as terras públicas fossem objeto de usucapião.

A lei estabeleceu que, no caso em que o notário, por omissão, negligência ou imprudência afetasse negativamente algum direito, seria responsabilizado administrativamente e ficaria obrigado a reparar o dano. O Código Civil também mudou a relação das aquisições de propriedade, isto é, a transferência somente se tornaria concreta no momento em que o título aquisitivo fosse passado ao nome do adquirente, junto ao Registro de Imóveis. Desta maneira, somente a escritura pública feita no cartório de notas, referente à aquisição do imóvel, não fazia prova de aquisição, tendo de ser levada a registro junto ao Registro de Imóveis (SANT'ANNA, 2008). Essa norma teve implicações importantes em termos de incentivar as posses e legitimá-las. Friedman (1999) e Holston (1993) chamaram a atenção para o fato de que esse aspecto do Código Civil permitiu a ampla e indiscriminada legitimação das posses, beneficiando sobremaneira os grupos sociais capazes de ter acesso e algum controle sobre os processos legais/judiciais.

A Lei Federal n. 5.621 de 4 de novembro de 1970 argumentava, em seu artigo $6^{\circ}$, inciso IV, que estava compreendida na organização judiciária a classificação, organização, disciplina e atribuições dos serviços auxiliares da justiça, incluindo neles os tabelionatos e ofícios de registros públicos. Com a abertura política do Brasil, a nova Constituição, promulgada em 1988, promoveu mudanças relevantes no regime jurídico dos notários. De acordo com Sant'Anna (2008), referindo-se ao artigo 236 da Constituição Federal, os serviços notariais e de registro são exercidos em caráter privado, por delegação do poder público. Três parágrafos desse artigo são de especial interesse.

O primeiro afirmava que a lei regulará as atividades, disciplinará a responsabilidade civil e criminal dos notários, dos oficiais de registro e de seus prepostos, e definirá a fiscalização de seus atos pelo Poder Judiciário (a Lei n. 8.935/94 regulamentou os aspectos dos serviços notariais e de registro deste parágrafo). $\mathrm{O}$ segundo declarava 
que a lei federal estabelecerá normas gerais para a fixação dos emulamentos relativos aos atos praticados pelos serviços notariais e de registro (a Lei n. 10.169/2000 regulamentou este parágrafo). Por fim, o terceiro parágrafo dizia que a atividade notarial e de registro depende de concurso público de provas e títulos, não se permitindo que qualquer serventia fique vaga, sem abertura de concurso de provimento ou de remoção, por mais de seis meses (a Lei n. 10.506/2000 alterou o artigo 16 da Lei n. 8.935/94 e regulamentou este parágrafo).

Atualmente, a legalidade institucional no que diz respeito à terra rural no Brasil depende de duas instituições principais, responsáveis, respectivamente, pelo registro e pelo cadastro de imóveis. $\mathrm{O}$ primeiro é atribuição dos cartórios e o segundo, do Instituto de Colonização e Reforma Agrária (Incra). Conforme Arruda (1999), o cadastro diz respeito às características físicas do imóvel e foi instituído por razões eminentemente fiscais, vinculadas à cobrança do Imposto Territorial Rural (ITR). Desde o Decreto n. 72.106, de 18 de abril de 1973, a rigor, todo imóvel rural deve ter matrícula junto ao Incra, a partir da qual este emite o Certificado de Cadastro de Imóvel Rural (CCIR), atestando a existência do imóvel rural. O registro do imóvel, por sua vez, cabe aos cartórios. O registro é um documento jurídico, sujeito à nulidade de provas, que atesta direitos de propriedade sobre imóveis declarados. Do ponto de vista institucional, esses dois procedimentos deveriam ser unos, mas não o são, fato que é um dos responsáveis pela fragilidade dos direitos de propriedade da terra no Brasil e por inúmeros conflitos fundiários (ARRUDA, 1999).

Nem mesmo em normas recentes, como a Lei n. 10.267/2001, nem nos decretos que a regulamentaram existe a obrigação para quem for comprar ou vender algum imóvel rural de apresentar o cadastro georreferenciado para lavrar a escritura pública. Há, assim, um conflito entre as duas instâncias institucionais flagrado por vários autores, tais como Guimarães (2008), Ferreira (2000) e Formicola (2000).

A Figura 1 procura sintetizar, através de uma visão esquemática, as inter-relações entre os órgãos do sistema de Administração Fundiária do Brasil, fruto deste conjunto de leis e regras que foram sendo estabelecidos ao longo do tempo. Percebe-se que não há vínculos entre o Incra e os municípios, fazendo com que haja muitos problemas fundiários na ligação entre terras rurais e urbanas.

Além disso, não existe uma instituição que centralize o cadastro e faça uma ligação com os órgãos do Judiciário que são responsáveis pela titulação dos imóveis. Não aparece no quadro, mas grande parte dos problemas fundiários no Brasil, tanto rurais quanto urbanos, quando não resolvidos na esfera administrativa, acabam na justiça e esta, por ter muitos processos em todos os seus tribunais, acaba por levar anos para julgá-los, fazendo com que quase sempre os casos relativos à terra, quer rural quer urbana, sejam julgados como fatos consumados.

Em resumo, no Brasil os processos de cadastramento e registro de imóveis rurais, embora estejam unos em termos jurídicos, estão divorciados em termos reais. Isso por duas razões. Primeiro, pela natureza declaratória dos imóveis inscritos nos cartórios e, em segundo lugar, pelo modo como se realiza a matrícula de um imóvel qualquer. Em relação à natureza declaratória, o sistema de registro brasileiro aproxima-se daquele chamado registro de terras, com efeito, negativo baseado em escritura, que, como se viu na seção 3, é típico da França, Bélgica e Holanda. Nele, o aspecto negativo é o fato de que a declaração e registro do imóvel estão sujeitos a nulidades por provas em contrário. Esse sistema somente oferece segurança fundiária se ancorado em um sistema de cadastro de imóveis preciso.

A separação real entre cadastro e registro e a natureza híbrida dos cartórios estão na raiz de algumas das dimensões do problema fundiário brasileiro. A ausência de cadastro e a necessidade de regulação dos mercados de terras foram atestadas por diversos estudos do Incra e do MDA. A melhor evidência da incapacidade que o Estado brasileiro vem tendo de efetivamente regular o mercado de terras consiste no estabelecimento da Portaria n. 558/99 do Incra, que impôs a todos os proprietários de imóveis com mais de 10.000 hectares a necessidade de apresentar a documentação 
Figura 1. Situação atual da Administração Fundiária no Brasil.

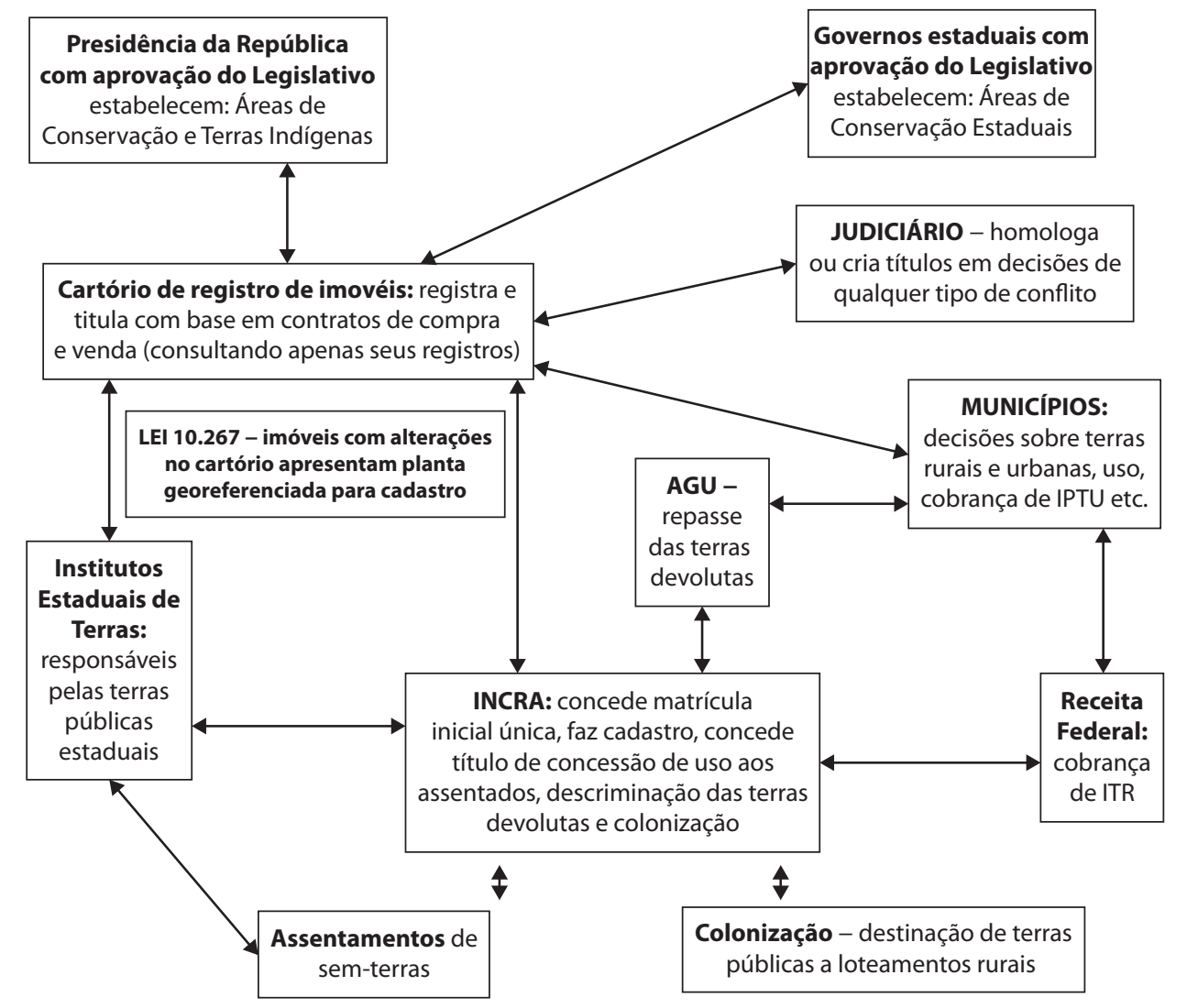

Fonte: Legislação em vigor e Reydon (2006).

comprobatória de seus imóveis, relatada por Sabbato (2001). Essa incapacidade se evidencia por dois aspectos da Portaria: a) o próprio ato de ter que requerer a documentação, pois o Estado deveria deter as informações necessárias de todos os imóveis e b) o fato de $1.438(46,9 \%)$ dos 3.065 imóveis não terem respondido, e que somam 46 milhões de ha (conforme se observa na Tabela 1). Dos 3.065 proprietários convocados, apenas 1.627 compareceram, fazendo com que 1.438 imóveis $(46,9 \%)$, perfazendo 46 milhões de ha, fossem excluídos do cadastro.

Tabela 1. Proprietários/detentores de imóveis rurais suspeitos de grilagem - Brasil e regiões.

\begin{tabular}{|c|c|c|c|c|}
\hline Região/UF & No imov. & $\%$ & Área (HA) & $\%$ \\
\hline Brasil & 1.438 & 100,0 & $46.156 .619,4$ & 100,0 \\
\hline Norte & 128 & 8,9 & $5.477 .825,1$ & 11,9 \\
\hline Nordeste & 152 & 10,6 & $4.247 .183,1$ & 9,2 \\
\hline Sudeste & 187 & 13,0 & $7.208 .982,5$ & 15,6 \\
\hline Sul & 29 & 2,0 & $690.607,9$ & 1,5 \\
\hline Centro-Oeste & 661 & 46,0 & $17.382 .403,7$ & 37,7 \\
\hline Endereço não informado & 281 & 19,5 & 11.149.617,1 & 24,2 \\
\hline
\end{tabular}

Fonte: Incra, listagem dos imóveis que não atenderam à notificação da Port. n. 558/99, de 21/12/2000. 
Durante o governo FHC (1994-2002) algumas iniciativas de regulação fundiária foram tentadas e deram origem a diversas publicações que mostram os problemas fundiários decorrentes da (des) regulação da propriedade privada. Um dos resultados é o relatório Livro Branco da Grilagem de Terras no Brasil que mostra, a partir de um levantamento preliminar da situação fundiária brasileira, a ausência de regulação da propriedade da terra no Brasil. Segundo o relatório (INCRA, 1999):

Em levantamento inédito, o Incra está mapeando a estrutura fundiária do país de modo a localizar, um a um, os casos de fraude e falsificação de títulos de propriedade de terras. A grilagem é um dos mais poderosos instrumentos de domínio e concentração fundiária no meio rural brasileiro. Em todo o país, o total de terras sob suspeita de serem griladas é de aproximadamente 100 milhões de hectares - quatro vezes a área do Estado de São Paulo ou a área da América Central mais México. Na Região Norte, os números são preocupantes: da área total do Estado do Amazonas, de 157 milhões de hectares, suspeita-se que nada menos que 55 milhões tenham sido grilados, o que corresponde a três vezes o território do Paraná. No Pará, um fantasma vendeu a dezenas de sucessores aproximadamente nove milhões de hectares de terras públicas (p. 2).
O mesmo relatório do Incra (1999) aponta para as causas deste problema ao afirmar que:

A fraude foi historicamente facilitada por algumas brechas institucionais como, por exemplo, a inexistência de um cadastro único. Os órgãos fundiários, nos três níveis (federal, estadual e municipal), não são articulados entre si. Ao contrário do que ocorre em outros países, no Brasil não existem registros especiais específicos para grandes áreas. Os dados dos cadastros federal e estaduais não estão cruzados e o cadastro federal, pela atual legislação, é declaratório. A correição (fiscalização) sobre os cartórios deixa a desejar (p. 15).

A ausência de regulação da propriedade da terra no Brasil, que é uma das facetas da questão agrária, consiste na prática do apossamento de terras, particularmente na Amazônia, que pode ser observado na Figura 2, obtido de Barreto (2008). Os dados cadastrais existentes, baseados nas declarações dos proprietários de terras que se cadastraram no Incra, mostram que, em 2003, 35\% dos 509 milhões de hectares de terra na Amazônia Legal estavam ocupados sob o direito de posse privado, seja como propriedade registrada ou como posse. Barreto (2008) afirma que o recente processo de criação de reservas federais e estaduais, de diferentes tipos, fez com que, hoje, $43 \%$ da Amazônia Legal esteja sob algum tipo de proteção.

Figura 2. Situação fundiária na Amazônia Legal considerando dados do Sistema Nacional de Cadastro Rural (2003) e áreas protegidas (2006).

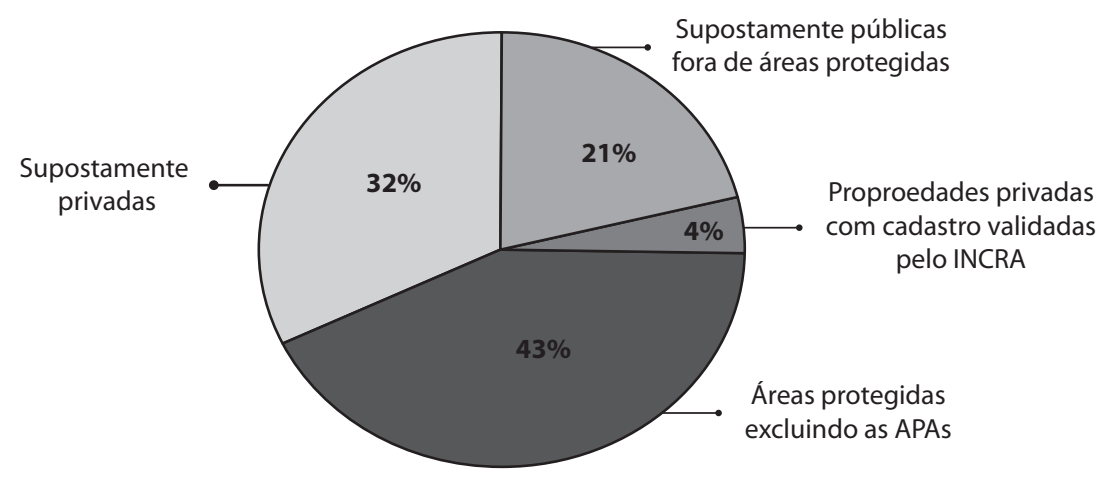

Fonte: Barreto (2008). 
Aproximadamente metade dessa área era de terras indígenas e a outra metade, Unidades de Conservação.

A informação decisiva que se obtém deste estudo é que apenas $4 \%$ das áreas privadas (20 milhões de ha) estão com os cadastros validados pelo Incra. Ou seja, na Amazônia, apenas $4 \%$ das terras privadas estão legalizadas. Há mais 158 milhões de ha (32\%) que são terras supostamente privadas sem validação de cadastro. E os $21 \%$ restantes não estavam em nenhuma dessas categorias e, portanto, são tecnicamente consideradas terras públicas sem alocação.

Mas a situação é mais complexa e incerta do que estes números indicam. Muitas das Áreas Protegidas estão fisicamente ocupadas por usuários privados, cujas reivindicações de ocupação podem ou não ter validade de acordo com a legislação complexa a ser apresentada. A grande área descrita como privada pelo sistema cadastral também está em dúvida. Dos 178 milhões de hectares declarados como propriedades privadas, $100 \mathrm{mi}-$ lhões de hectares podem estar baseados em documentação fraudulenta. Outros 42 milhões de hectares dessa área são classificados a partir de declarações cadastrais como posse, que podem ou não ser passíveis de regularização fundiária, novamente dependendo das suas circunstâncias de tamanho, história e localização.

Apesar disso, não se percebia, por parte dos supostos interessados em aperfeiçoar técnica e organizacionalmente o sistema de cadastro e registro de imóveis, nenhum movimento político substancial para fazê-lo. É como se a dimensão do caos fundiário dado pelos problemas de legalidade dos títulos e escrituras de propriedade servisse aos interesses de grupos ou segmentos sociais específicos. A convivência secular com o problema de titularidade da propriedade rural e a aversão e resistência às reformas efetivas nas instituições por elas responsáveis revelam amplos e fortes interesses econômico-sociais que bloquearam a mudança institucional. Isto está mudando?

\section{Proposta institucional para a regulação dos mercados de terra: a governança fundiária}

No Brasil, apesar da existência de legislação e de responsabilidades institucionais para regular o acesso à terra, estas são sempre ambíguas ou permitem o não cumprimento impune, o que sempre beneficia os especuladores e os grileiros de terras em detrimento do seu melhor uso coletivo.

Isso decorre do fato de que, no Brasil, a especulação com terras tem forte presença nos setores rural e urbano, estimulada em parte pela ausência de instituições públicas capazes de controlar seus usos. Apesar disso, há um conjunto de tendências recentes que colocam um contexto favorável à mudança institucional em favor da regulação fundiária:

1. a questão ambiental e as pressões internas e externas na defesa das florestas brasileiras, o que exige controle sobre a ocupação humana de vastas áreas do território brasileiro. Esse aspecto tem estimulado a percepção do papel negativo sobre o ambiente de uma ocupação desregulada e livre do território. Uma expressão dessa força foi a aprovação recente pelo governo federal do Decreto n. 6.169, de 17 de setembro de 2009, que estabeleceu áreas geográficas do País onde a plantação da cana é proibida.

2. A questão da segurança nacional gera a percepção por parte do Estado nacional da importância para a integridade territorial e para o efetivo controle público do território de registros/cadastros adequados das terras públicas e privadas. O exemplo mais recente foi a aprovação, pelo STF, da demarcação das terras indígenas ocupadas por arrozeiros no estado do Pará;

3. A questão da limitação das terras de estrangeiros que tem sido objeto de controvérsias há muitos anos e em 2009 ganhou novo arcabouço legal, por meio do Projeto de Lei n. 4.440. O projeto pre- 
vê que estrangeiros e empresas brasileiras controladas por estrangeiros não poderão adquirir área rural que tenha mais de 50 módulos rurais. Com a finalidade de coibir a especulação, o projeto impede a aquisição por estrangeiros de terras que não estejam vinculados aos seus objetivos empresariais previstos em estatuto ou contrato social e aprovados pelo Ministério do Desenvolvimento Agrário;

4. A própria dinâmica do agronegócio exige, como condição de competitividade, melhor regulação da terra rural no Brasil, haja vista o interesse de capitais estrangeiros em adquirir terras e produzir em solo nacional. Isso demanda melhores direitos de propriedade da terra.

Esses movimentos ainda estão difusos, disseminados por amplas e não raro contraditórias forças sociais. Seu resultado por consequência somente é perceptível em eventos isolados e que só ganham significado quando articulados, tais são as recentes decisões do judiciário em relação aos cartórios, às medidas administrativas do próprio Incra e às leis aprovadas no congresso nacional. Os principais exemplos destas propostas são as seguintes, instituídas desde 1995:

a) Portaria n. 558/1999, que visou o recadastramento utilizando notificações para imóveis com área total igual ou superior a 10.000 ha em todo o País. Como resultado dessa iniciativa, verificou-se que mais de $50 \%$ dos imóveis desta categoria no cadastro eram inexistentes;

b) Portaria n. 596/2001, que objetivou o recadastramento também utilizando notificações para imóveis com área total maior ou igual a 5.000 ha e até $9.999,9$ ha, em 68 municípios do Brasil. Nessa etapa foram selecionados os municípios que apresentaram maior número de irregularidades na primeira fase de recadastramento (Portaria n. 558/1999); c) Lei n. 10.267/2001, que propõe um reordenamento fundiário por meio do Cadastramento Nacional de Imóveis Rurais (Cnir);

d) Lei n. 11.952/09, que regularizou a custo zero as posses de até 400 ha e pôs à venda as posses de entre 401 e 1.500 ha (os posseiros têm que comprovar que vivem no lote desde 2004);

e) O governo federal implementou o Programa Terra Legal, por meio do Decreto n. 6.992, de 28 de outubro de 2009. Ele regulamenta a Lei n. 11.952, de 25 de junho de 2009, para dispor sobre a regularização fundiária das áreas rurais situadas em terras da União, no âmbito da Amazônia Legal, definida pela Lei Complementar n. 124, de 3 de janeiro de 2007, e dá outras providências;

f) Criação de inúmeras APA's (Áreas Protegidas) na forma de Unidades de Conservação (baseada na Lei n. 9.985 de julho de 2000) para proteção na beira das principais estradas em construção na região Amazônica;

g) O governo do estado do Pará, através do Iterpa, desenvolveu um intenso programa na área de governança fundiária com resultados expressivos. Cabe destacar as seguintes principais atividades: regularização fundiária georreferenciada; consolidação dos títulos nos cartórios, no Incra (CCIR e Cnir) e no Instituto de Terras e cancelamento de títulos ilegais.

Todas convergem para o movimento de mudança institucional em favor de melhores mecanismos de demarcação, registro e imposição de direitos de propriedade da terra, que, além de diminuírem a especulação com as terras rurais e urbanas, façam com que a dinâmica de ocupação leve em conta os melhores usos sociais e ambientais. Com base nessa evidência, torna-se imperativo regular o mercado de terras efetivamente para que funcione melhor e que os processos especu- 
lativos não se expandam excessivamente. Para o World Bank e para o BID, a regulação dos mercados é o foco principal de suas atividades nessa área. Num relatório publicado pelo Banco Mundial, Burky e Perry (1998) propõem numa linha muito semelhante à das Nações Unidas:

as instituições formais dos mercados de terras deveriam incluir o registro dos imóveis, títulos de propriedades e o mapeamento dos imóveis. Quando as instituições forem desenhadas são quatro características que devem ser levadas em conta:

- Definição e clara administração dos direitos de propriedade dos imóveis;

- Mecanismos simples para identificar e transferir direitos de propriedade;

- Compilação cuidadosa dos títulos de propriedade e livre acesso a estas informações;

- Mapeamento dos imóveis (p. 37).

Mais recentemente, a literatura internacional vem caracterizando esta mudança institucional e de atitude como a busca de uma adequada governança ${ }^{13}$ fundiária, conforme, entre outros, FAO (2008) e Doelinger (2010). Nesta, a sociedade em conjunto com o Estado, faz a gestão das terras tomando as decisões sobre acesso à terra, seus usos e como os interesses que competem pela terra são gerenciados.

No Brasil há pelo menos duas experiências de utilização de informações digitalizadas e cadastrais que merecem ser citadas: a do caso do município de Lucas do Rio Verde para fins de gestão ambiental e a do Instituto de Terras do Pará (Iterpa) para cadastramento e titulação. Marques; Mancilla; Figueiredo; Bonjour (2009) analisaram

13 FAO (2008) trabalha com uma definição adequada de governança da terra segundo a qual: "Gobernanza is the system of values, policies, and institutions by which a society manages its economic, political and social affairs trought interactions within and among the state, civil society and private sector. Land gobernanza concerns the rules, processes and organizations through which decisions are made about access to land and its use, the manner in which the decisions are implemented, and the way that competing interest in land are managed" (p. 9). o caso de Lucas do Rio Verde, município localizado no estado de Mato Grosso, cujo projeto de desenvolvimento sustentável local tem sua base no mapeamento e caracterização físico-econômica das pequenas propriedades rurais utilizando imagens de satélite e o georreferenciamento. Tal projeto busca envolver, em compromisso de longo prazo, os agricultores na recuperação de áreas de reserva legal degradadas e na sua manutenção. A estratégia utilizada envolveu sofisticada ação coletiva, mobilizando vários atores, entre os quais os próprios pequenos produtores, o Estado, associações de representação patronal de classe, ONGs e empresas privadas ligadas ao agronegócio.

A segunda experiência envolveu o governo do estado do Pará, através do Iterpa. Este desenvolveu um intenso programa na área de governança fundiária com resultados expressivos, cabendo citar as que julgamos mais importantes: regularização fundiária georreferenciada; consolidação dos títulos nos cartórios, no Incra (CCIR e Cnir) e no Instituto de Terras, bem como o cancelamento de títulos ilegais. A sua metodologia pode ser encontrada em Instituto de Terras do Pará (2006) e em Reydon e Costa (2010), ambas importantes fontes de inspiração para a presente proposta, apresentada a seguir.

Ela se apoia na execução de projeto que utilize uma metodologia simplificada baseada nas imagens de satélite e na informação dos importantes atores sociais da região. Associada ao mapeamento em técnicas GIS para a consolidação das informações, o principal objetivo é utilizar metodologia participativa que clarifique propriedades privadas, coletivas, posses e terras devolutas para fins de registro, em regiões previamente definidas, utilizando imagens de satélite. A proposta se materializa nas seguintes etapas:

a) Escolha participativa de localidade com ordenamento legal da titularidade da terra duvidosa - com presença de posseiros, proprietários privados, terras comuns e terras devolutas para aplicação do piloto (s);

b) Obtenção e tabulação das informações sobre a propriedade nas diferentes fontes - Incra, cartórios e outros (Lei n. 10.267) 
c) Obtenção de imagem de satélite da região na melhor escala possível;

d) Utilizando a imagem de satélite, verificar a titularidade dos imóveis, localização precisa e identificar as terras devolutas em reuniões com a participação das comunidades organizadas da região;

e) Identificar os possíveis conflitos sobre a titularidade da terra;

f) Analisar a possibilidade de que, com consenso sobre a titularidade da terra, haja a adjudicação dos títulos das propriedades;

g) Criar o cadastro mapeado e com localização precisa dos imóveis pesquisados

h) Expandir a proposta a outros municípios e desenvolver metodologia que viabilize a execução de trabalhos no conjunto do País.

\section{Considerações finais}

$\mathrm{O}$ artigo mostrou a relevância e pertinência da abordagem institucional da questão fundiária, particularmente quando ela se detém na análise dos fatores de bloqueio da mudança. Forças sociais que ganham com o status quo e podem vir a ser perdedores potenciais em caso de mudança institucional se articulam para preservar as instituições vigentes, geralmente ao preço de maior ineficiência e ineficácia.

O artigo também mostrou a importância e a diversidade de instituições de registro e cadastro de imóveis no plano internacional. Em seguida, contrastou-as com aquelas predominantes no Brasil, fazendo observar a ineficiência dessas instituições neste País. Apesar das forças de bloqueio ainda serem hegemônicas, o artigo se refere a fatores de mudança que podem mover a balança em favor de maior eficiência e equidade na política fundiária brasileira. Em particular, a questão ambiental, os interesses vinculados à segurança nacional e a nova dinâmica dos capitais agroindustriais, com a presença crescente de atores internacionais. Esses fatores pressionam por mudança institucional, que vem sendo ofertada, de forma esparsa e tópica, pelo estado nacional.
Nesse esforço, foi apresentada uma proposta de governança fundiária adequada ao novo contexto de mudança institucional, que pode contribuir para uma melhor eficiência e equidade na distribuição e posse da propriedade fundiária no Brasil. Na verdade, a proposta converge com algumas experiências locais/regionais já em curso e delas se aproveita, oferecendo um conjunto de prescrições ordenadas cujo âmbito de aplicação é mais geral. Elas são financeiramente exequíveis porque não partem necessariamente de exaustivo e custoso levantamento de informações de títulos e de documentação formal independentemente dos interessados (posseiros e proprietários), além do que seus custos podem ser divididos entre os agentes interessados na regulação fundiária, como ilustrou o caso de Lucas de Rio Verde. Ela é interessante também porque está em consonância com a visão de que o desenvolvimento territorial será mais adequadamente implementado se os processos decisórios forem delegados, em muitos aspectos, aos atores locais/regionais, a quem caberá, no final, a implementação dos processos efetivos de regularização e regulação fundiários.

A proposta não está, contudo, isenta de dificuldades, a mais séria delas a da exigência de forte engajamento e participação dos agentes sociais envolvidos. Em outras palavras, a proposta pressupõe o acúmulo de capital social para que se possam viabilizar os projetos de regulação fundiária. Dada a notória fragilidade da organização da ação coletiva em termos locais no Brasil, contrastada à força dos interesses econômicos locais, este não é um desafio trivial à nova governança fundiária.

\section{Referências bibliográficas}

ALSTON, L. A framework for understanding the New Institutional Economics. In: First brasilian seminar of new institutional economics. São Paulo, 1998.

ALSTON, L.; EGGERTSSON, T. e NORTH, D. Empirical studies in institutional change. Cambridge: Cambridge University Press. 1996.

ARRUDA, R. M. O registro de imóveis e o cadastro. Revista opinião jurídica, n. 29, p 13-18, 1999. 
AZEVEDO, P. F. e BIALOSKOSKY, S. Conflitos fundiários $e$ direitos de propriedade: implicações sobre o uso da terra. Mimeo. p. 27, 2002.

BARRETO, P. Quem é dono da Amazônia? Belém. IMAZON. [Internet: coletado em 18/05/11. http://www. ibcperu.org/doc/isis/10458.pdf.]. 2008.

BELIK, W:; GUEDES, S. N. R. e REYDON, B. Instituições, ambiente institucional e políticas agrícolas. In: RAMOS, P. (Org) Dimensões do agronegócio brasileiro: políticas, instituições e perspectivas . Brasília: NEAD/MDA, p. 103-140, 2007.

BINSWANGER, H. e PINGALI, P. Population density, market access and farmergenerated technical change in SubSaharan Africa. Washington: World Bank, 1986.

BROCKMEIR, T. Legal order and economic (under) development - a contribution to the theory of property rights. Economics, v. 58, p. 7-45, 1998.

BURKY,S. J. e PERRY, G. E. Beyond the Washington Consensus: institution matter. World Bank: Latin America and Caribbean Studies Viewpoint. Washington, 1998.

BYAMUGISHA, F. F. K. How long registration affects financial development and economic growth in Thailand. Washington: World Bank Policy Research Working Paper 2241. 1999.

CLAWSON, M. The bureau of land management. New York: Praeger publishers, 1971.

COASE, R. The problem of social cost. In: COASE, R. The firm, the market and the law. Chicago: The University of Chicago Press, p 95-156, 1988.

COLE, D. H. e GROSSMAN, P. Z. The meaning of property rights: law versus economics. Land Economics, v. 78, n. 3, p 317-330, 2002.

COMMONS, J. R. Institutional Economics. New Bruneswick (USA): Transactions Publishers, 2003.

CORRÊA, H. e IGLESIAS, S. União doa pequenas terras a posseirosna Amazônia. Folha de São Paulo. São Paulo, 23 de janeiro de 2009. Brasil, p.8.

DEININGER, K. Land policies for growth and poverty reduction. Washington: World Bank and Oxford University Press. 2003.

DEININGER, $K$. et al. "The land governance framework: methodology and early lessons from country pilots". In: Innovations in land rights recognition, administration and governance. Washington: World Bank, GLTN, FIG and FAO. 2010.

DEKKER, H. A. L. In pursuit of land tenure security. Amsterdan: Pallas publications. 2005.

DEKKER, H. A. L. The invisible line. London: Ashgate. 2003
DE JANVRY, A. e SADOULET, E. Access to land and land policy reforms. Helsink: World Institute for Development Economics Research, 2003.

DEMSETZ, H. Toward a theory of property rights. The American Economic Review, v. 58, n. 2, p. 347-359,1967.

DIAS, E. A. Cartórios brasileiros: por que não mudar?. Jornal Folha de São Paulo. São Paulo, 15 de junho de 2009. Opinião, p. 3.

ECHEVERRIA, C. Desarrollo territorial rural en América Latina e el Caribe. Washington: BID, 2003.

EGGERTSSON, T. Economic behavior and institutions. Cambridge: Cambridge University Press, 1990.

FAO Land Tenure and Managment Unit. 2009. Towards voluntary guidelines on responsible governance of tenure of land and other natural resources. Land Tenure (Working Paper 10). Rome: Food and Agricultural Organization of the UN. 2009.

FERREIRA, J. F. Para onde vão os cartórios? Revista de Direito Imobiliário, v. 1, n. 23, p. 125-133, 2000.

FISCHEL, W. A. The economics of zoning laws: a property rights approach to American land use controls. Baltimore: Johns Hopkins University Press.1985.

FITZPATRICK, D. Land policy in post-conflict circumstances: some lessons from East Timor. Sidney: Australian National University, 2001.

FORMICOLA, T. O notariado no Brasil e no mundo. Revista de Direito Imobiliário, v. 1,n. 23,p. 85-92, 2000.

GALAL, A. e RAZZAZ, O. Reforming land and real estate markets. Washington: World Bank Policy Research Working Paper 2616, 2001.

GALIANI, S. e SCHARGRODSKY, E. - Property rights for the poor: effects of land titling. Buenos Aires: Centro de Investigaciones in Finanzas. Documento de trabajo n. 06/2005. Disponível em: www.utdt.edu/departamentos/empresarial/cif/cif.html

GESSA, S. D. "Participatory Mapping as a tool for empowerment". In: International Land Coalition. Rome, Italy. Disponível em: www.ifad.org/pub/map/PM_web.pdf. 2008.

GORDILLO, G. DE JANVRY, A. e SADOULET, E. Entre el control político y la eficiência: evolución de los derechos de propriedad agrária em México. Revista de la CEPAL, n. 66. 1999.

GREIF, A. The emergence of institutions to protect property rights. Mimeo. Standford University. p. 87, 2003.

GUEDES, S. N. R. Análise comparativa do processo de transferência de terras públicas para o domínio privado no Brasil e EUA: uma abordagem institucionalista. Revista de Economia, v. 32, n. 1, p. 7-36, 2006. 
INCRA Livro Branco da grilagem de terras no Brasil. Capturado da internet em 21/06/2011- http://www.incra.gov.br/ portal/index.php?option=com_docman\&Itemid=140.199.

GUIMARÃES, R. E. R. Georreferenciamento de imóveis rurais: aspectos legais, sociais e econômicos. Revista de Direito Imobiliário, v. 1, n. 65, p. 76-92, 2008.

HOLSTON, J. Legalizando o ilegal: propriedade e usurpação no Brasil. Revista Brasileira Ciências Sociais, n. 21 ano 8 fevereiro de 1993. São Paulo. 1993.

INSTITUTO DE TERRAS DO PARÁ. ITERPA. Cadastro de Georreferenciamento e Regularização Fundiária de Imóveis Rurais do Estado do Pará: Manual de Procedimentos. Belém. ITERPA 2006.

JOHNSON, O. E. G. Economic analysis, the legal framework and land tenure systems. Journal of Law and Economics, v. 15, p. 259-76, 1972.

JOIREMAN, S. F. Property rights and the role of the state: evidence from the Horn of Africa. The Journal of Development Studies, v. 1, n. 38, p. 1-28, 2001.

JUNQUEIRA, M. Breve introdução histórica ao direito territorial público brasileiro. Brasília: Cadernos da UNB, p 15-20, 1978.

KHAN, M. H. Power, property rights and the issue of land reform: a general case illustrate with reference to Bangladesh. Journal of Agrarian Change, v. 4, n. 1, p. 73-106, 2004.

LIBECAP, G. D. Contracting for property rights. Cambridge: Cambridge University Press, 1998.

MARQUES, A. K.; MANCILLA, G. D. FIGUEIREDO, A. M. R. e BONJOUR, S. C. M. A caracterização ambiental da pequena propriedade rural de Lucas de Rio Verde, Mato Grosso. Revista de Política Agrícola, n. 3, p. 70-84, 2009.

MINISTÉRIO DO DESENVOLVIMENTO AGRÁRIO- Estatística do meio rural 2008. Brasília: MDA/DIEESE, 2008.

MORAES, A. C. R. Bases da formação territorial do Brasil: o território colonial brasileiro no "longo" século XVI. São Paulo: Hucitec. 2000.

MORAES SILVA, M. A. Errantes do fim do século. São Paulo: Fundação Editora da UNESP, 1999.

MUELLER, B. A evolução histórica dos direitos de propriedade sobre terras no Brasil e nos EUA. História Econômica e história de empresas, v. 9, p. 23-54, 2006.

NORTH, D. Institutions, institutional change and economic performance. Cambridge: Cambridge University Press. 1990.

OSÓRIO SILVA, L. Terras devolutas e latifúndio. Campinas: Editora da Unicamp. 1996.
OSÓRIO SILVA, L. As leis agrárias e o latifúndio improdutivo. São Paulo em Perspectiva, v. 11, n. 2, p. 15-25, 1997.

RAMOS, D. e PALME, U. W. Regularização Fundiária. Revista Agroanalysis, v. 27,n. 9, 2007.

REZENDE, G. C. Políticas trabalhistas, fundiária e de crédito agrícola no Brasil: uma avaliação crítica. Revista e Economia e Sociologia Rural, v. 44, n. 1, p. 47-78, 2006.

REZENDE, G. C. e GUEDES, S. N. R. Formação histórica dos direitos de propriedade da terra no Brasil e nos EUA e sua relação com as políticas agrícolas atualmente adotadas nesses países. In: COELHO, A. B.; TEIXEIRA, E. C. e BRAGA, M. J. (ORG) - Recursos naturais e crescimento econômico. Viçosa: Editora da Universidade Federal de Viçosa. p. 279-311, 2008.

REPORTAGEM LOCAL Tamanho do Pará no cartório é 4 vezes maior. Jornal Folha de São Paulo. São Paulo, p. 6, 29 de junho de 2009. Brasil.

REYDON, B. P. e PLATA, L. A. Intervenção estatal no mercado de terras: a experiência recente no Brasil. Campinas: NEAD. p. 172. (Estudos NEAD, n.3), 2000.

REYDON, B. P. e CORNÉLIO, F. N. M. Mercados de terras no Brasil: estrutura e dinâmica. Brasília: MDA. NEAD-DEBATE 7, 2006.

REYDON, B. P. A regulação institucional da propriedade da terra no Brasil: uma necessidade urgente. In: RAMOS, P. Dimensões do agronegócio brasileiro: políticas, instituições e perspectivas. Brasília: MDA (NEADEstudos 15), 2007.

REYDON, B. P. e COSTA, A. S. Cadastro e regulação da propriedade da terra: um estudo do seu custo com base na legislação em vigor. Revista de Política Agrícola, ano XX n. 1 jan.fev.mar.-2011, in press. Brasília.

SABBATO, A. Perfil dos proprietários/detentores de grandes imóveis rurais que não atenderam à notificação da Portaria 558/99. [Internet:http://www.incra.gov.br, capturado em 03 de agosto de 2003].

SANT'ANNA, G. C. Fatos históricos e jurídicos determinantes da configuração contemporânea dos serviços notariais. Revista de Direito Imobiliário, v. 1, n. 65, p. 39-60, 2008.

SCOLESE, E. 14\% da Amazônia é terra de ninguém. Jornal Folha de São Paulo, São Paulo, p. 4, 27 de junho de 2008. Brasil.

SOTO, H. The mistery of capital: Why capitalism triumphs in the West and fails everywhere else. New York: Basic books, 2000.

UN-ECE-Land Administration Guidelines. Geneva, 1996.

VOGELGESANG, F. Los derechos de propriedad y el mercado de la tierra rural en América Latina. Revista de la CEPAL, v. 58. p. 95-114, 1996. 
